\title{
The category effect in visual search: Practice effects on catch trials
}

\author{
HOWARD S. HOCK, ALAN ROSENTHAL, and PHILIP STENQUIST \\ Florida Atlantic University, Boca Raton, Florida
}

\begin{abstract}
Two experiments involved searching for digit or letter targets in displays of letters. On a catch trial following between-category search (for a digit among letters), a digit other than the target was presented in the display. The occurrence of incorrect target-present responses and slow, correct target-absent responses on this catch-trial decreased as the amount of preceding practice increased. This practice effect was not accompanied by shifts in decision criteria predicted from explanations of the category effect that stress between- and within-category differences in physical resemblance. Also, the effect of practice on catch trials was not accompanied by changes in speed of category-level vs. specific-level identification predicted from level-of-identification explanations of the category effect. An alternative explanation was proposed. It distinguished between attention to attributes shared by members of the target's category (resulting in the catchtrial effect) and attention to attributes specific to the target (resulting in its elimination as a function of practice).
\end{abstract}

The alphanumeric category effect refers to evidence that subjects can search through a display for an alphanumeric target at a faster rate when the nontarget items in the display belong to a different category from that of the target than when they belong to the same category as the target. This difference in search rate is indicated by a smaller effect of display size on target-present and target-absent reaction time for between-category than within-category search.

The original explanation for the category effect focused on the level of identification for the items in the display. Brand (1971), Ingling (1972), and Gleitman and Jonides (1976) proposed that between-category search rate was faster than within-category search rate because categorylevel identification of the target is easier than specificlevel identification. As a result of this assumed difference in difficulty, Jonides and Gleitman (1972) and Egeth, Jonides, and Wall (1972) have suggested that the categorylevel identification of the target can be based on parallel processing of display items (as in between-category search), whereas the specific-level identification of the target requires serial processing of the display items (as in within-category search). However, evidence that specific-level identification is faster (Dick, 1971) and more accurate (Nickerson, 1973) than category-level identification directly contradicts the assumption that categorylevel identification is easier.

The research reported in this paper was supported by Grants DAHC1978-G-0002 and MDA903-82-C-0317 from the Army Research Institute. The authors thank Clay Cavedo and Gerald O'Rourke for their help in analyzing the experimental data, and Larry Malcus, John Duncan, and John Jonides for their careful reading of an earlier version of the manuscript. Philip Stenquist is currently at Southern Illinois University.

The mailing address of the other authors is: Department of Psychology, Florida Atlantic University, Boca Raton, FL 33431.
More recent explanations of the category effect have focused on how the discriminability of the target from nontarget items in the display affects the speed with which items can be rejected as nontargets. Gleitman and Jonides (1978) have argued that display items represented by both category-level and specific-level codes can be more easily rejected as nontargets when they differ from the item being searched for by both the category-level and specificlevel codes (as in between-category search) than when they differ by only the specific-level code (as in within-category search). Duncan (1983) has argued that the alphanumeric category effect is due to differences in between-category and within-category resemblance. That is, on the average, members of the digit and letter categories resemble members of their own category more than they resemble members of the other category. As a result, betweencategory search would be faster than within-category search because items in the visual display are easier to reject as nontargets when they are easily discriminated from the target (as in the between-category col tition) than $_{2}$ when they are relatively difficult to discriminate from the target (as in the within-category condition). Duncan's (1983) physical-resemblance explanation of the category effect was based on his failure to replicate Jonides and Gleitman's (1972) oh-zero effect and Corcoran and Jackson's (1977) evidence that the difference in search rate for between-category and within-category conditions was eliminated when both conditions involved targets that were difficult to discriminate from nontarget items in the display. The latter result, which has also been reported in a recent experiment by Krueger (1984), provides strong support for Duncan's (1983) explanation of the category effect, but is not consistent with explanations that assume that performance in the visual search task is based on a search through category-level and specific-level memory 
codes for the items in a display (Francolini \& Egeth, 1979; Gleitman \& Jonides, 1978). Implicit in these memorysearch explanations is the assumption that the performance differences in between-category and within-category search do not depend on differences in the relative difficulty of category-level or identity-level coding of display items. This implies that matching between-category and within-category conditions in target-to-nontarget resemblance should not eliminate the category effect. The results of Corcoran and Jackson's (1977) and Krueger's (1984) experiments indicate that this is not the case.

The experiments reported in this paper examined a phenomenon associated with the category effect, namely subjects' tendency to make false-alarm errors on catch trials. In standard between-category search, there are no trials in which the display includes an item that belongs to the same category as the target(s) without that item's corresponding to one of the target characters specified prior to the display. The catch trial violates this rule. For example, if the targets specified in between-category search were " 2 "' and " 4 ," the display might include a " 3 " among an array of letters. When Gleitman and Jonides (1976) presented such a catch trial (there were six items in their catch-trial display) after 192 standard between-category trials, they found that 14 of 16 subjects made false-alarm responses. In contrast, no subjects in the within-category condition made a false-alarm response when the 193rd trial included a nontarget item that had previously been used only as a target.

The catch-trial effect, like the difference in the rate of between-category and within-category search, can be explained by either the level at which display items are identified or the physical resemblance between target and nontarget items. The level-of-identification explanation would attribute the catch-trial effect in between-category search to subjects' initiating a target-present ("yes') response when they detected an item belonging to the target's category, without first identifying that item at the specific level. The physical-resemblance explanation would attribute the catch-trial effect to the perceptual confusion of the target with the nontarget item in the display that was most difficult to discriminate from the target, viz, the item that belonged to the target's category. Prior to the catch trial, most of the nontarget items in the between-category condition were dissimilar to the target (they belonged to a different category). Subjects could therefore adopt a relatively loose criterion in deciding whether items in the display corresponded to the target, resulting in a high likelihood of their making a false-alarm response on the unexpected catch trial.

The experiments reported in this study examined the effect of practice on the catch-trial effect. Regardless of whether practice increases or decreases the effect, we could examine the implications of this change for performance on the standard trials preceding the catch trial. According to the physical-resemblance explanation of the category effect, a change in the rate of false alarms on the catch trial would be due to a change in decision criterion. If practice results in the development of a less stringent decision criterion, subjects' rates of false alarms would increase. This change should be accompanied by a decrease in the time spent processing each display item on the standard trials preceding the catch trial. The latter would be indicated if practice speeded up the search rate on standard between-category trials. Slower search rates and fewer false alarms on catch trials would be expected if a more stringent decision criterion developed with practice.

Our method of evaluating the level-of-identification explanation was somewhat different. In Experiment 2, we used the difference in reaction time between particulardigit search (e.g., look for a "4") and any-digit search (look for any digit) to infer specific-level target identification. According to the level-of-identification explanation, this difference should decrease (indicating categorylevel target identification) as the catch-trial effect increases.

\section{EXPERIMENT 1}

Duncan's (1983) version of the physical-resemblance explanation was proposed only for the case in which one target character is specified prior to each trial. He argued that, when more than one character is specified prior to a trial, performance in between-category search is based on the category-level identification of the display items. Since Gleitman and Jonides's (1976) catch-trial data were obtained when two targets were specified prior to each display, the starting point for our research was to test the catch-trial effect under conditions in which each display was preceded by the specification of only one target. If the catch-trial effect had not been obtained, it would have provided strong support for Duncan's (1983) argument that category-level identification does not occur when between-category search involves only one target. Since the catch-trial effect was obtained, we had the opportunity to observe whether practice would influence the size of the catch-trial effect.

\section{Method}

Subjects. A total of 48 subjects, undergraduate students at Florida Atlantic University, voluntarily participated in this experiment. Each was paid $\$ 2$.

Stimuli. The experiment involved both between-category and within-category search. Subjects working in the between-category condition looked for a single target drawn from a set of eight possible digits: 2 through 9 . Subjects working in the within-category condition looked for a single target drawn from a set of eight possible target letters: A, B, G, L, P, R, S, and Z. The nontarget items in both between-category and within-category displays were drawn from the set: C, D, E, F, H, J, K, M, N, O, V, Y.' ${ }^{\text {The target }}$ and nontarget characters were the same as those used by Gleitman and Jonides (1976).

Each display comprised $1,2,4$, or 6 characters, whose possible locations were defined by the 12 locations of an imaginary clockface. For displays that included a target character, each of the eight targets in either between-category or within-category search was presented equally often at each of the 12 clockface positions, yielding 96 target-present displays. Nontarget letters were assigned to each 
target-present display to create the display sizes of $1,2,4$, or 6 characters (there were 24 of each display size in the target-present condition). The nontarget letters were randomly selected from the set of 13 nontarget letters indicated above. They were assigned randomly to various clockface locations, but with the following constraints: (1) There were no repetitions of nontarget letters within a single display, (2) one nontarget letter was always placed in the position diametrically opposed to the target (except for the one-item display) in order to maintain a constant visual angle, and (3) each nontarget letter appeared equally often. This set of 96 target-present displays was matched by another set of 96 target-absent displays that were created by substituting, for each target, a randomly selected letter from the set of 13 nontarget letters (once again with the restriction that the same character could not appear more than once in each display). This resulted in a total set of 192 displays, each involving black characters (Univers 53) presented on a white background.

The stimulus presented immediately after the experimental sequence was the catch trial, which was identical for each subject. There were six display items on this trial. In the between-category condition, the target specified prior to the display was a " 3 " and the digit presented in the display was a "5." In the within-category condition, the target specified prior to the catch-trial was an " $\mathrm{A}$ " and the display included the letter " $B$." The latter represented the first instance in which a letter that had theretofore been used only as a target was being used as a nontarget item in a display.

Design. Subjects were required to respond "yes" when the target specified prior to each trial appeared in the display. Otherwise, they were to respond "no." With the exception of the catch trial at the end of the experimental session, if the specified target was not present in the display, no other member of the target set was present.

The set of 96 target-present and 96 target-absent stimuli was ordered randomly within four blocks of $\mathbf{4 8}$ trials. Matching sequences were generated for the between-category and within-category conditions. Represented within each block of 48 were an equal number of target-present and target-absent displays for each of the four display sizes, which were also equally represented. Each block of 48 included, in random order, 24 displays that required "yes" responses (target-present displays) and 24 that required "no" responses (target-absent displays).

One group of 24 subjects received two blocks of 48 trials (Group 96); a second group of subjects received four blocks of 48 trials (Group 192). Within each group, 12 subjects participated in between-category search and 12 participated in within-category search. For Group 192, four orders of the four blocks of $\mathbf{4 8}$ trials were formed (Latin square), with each subject assigned to one of the four orders. The catch trial was presented on the 193rd trial. The two blocks of 48 trials presented to subjects in Group 96 were balanced so that all 192 displays presented to Group 192 were equally represented in the data collected for Group 96. The catch trial for Group 96 was presented on the 97th trial. As in Group 192, each of the four blocks of 48 trials preceded the catch trial equally often. The main experimental trials were preceded by 48 warm-up trials for both Group 96 and Group 192.

Procedure. At the start of the experimental session, subjects were shown the target and nontarget characters that were to be presented in the experiment. They were informed that the display size would vary in a random manner, and that a target would be verbally specified prior to each display. When the specified target was present in the display, the subjects were instructed to respond by pressing a button labeled "Yes." When the specified target was not present in the display, they were to respond by pressing a button labeled "No." The assignment of the subjects' right and left hands to the two responses buttons was balanced according to hand dominance; half the subjects pressed the "Yes"' button with the dominant hand, and half pressed it with the nondominant hand.

The stimuli were back-projected onto a translucent screen by a Kodak Ektagraphic slide projector. A Uniblitz electronic shutter limited the presentation of each slide to $200 \mathrm{msec}$. When viewed from a distance of $90 \mathrm{~cm}$, each alphanumeric character intercepted a visual angle of $0.2^{\circ}$ (horizontally). The imaginary clockface used to construct the displays was centered at the point of fixation, which was marked on the screen. If the clockface had been real, it would have intercepted a visual angle of $3.4^{\circ}$.

Each trial began with the experimenter verbally specifying a target. This was followed by the advance of the slide tray, which provided subjects with an auditory signal to look at the fixation point. The subjects were instructed to respond as quickly as possible, and were informed that some errors were expected. Corrective feedback was provided after each error.

\section{Results}

Mean reaction times for correct responses and percentage errors, excluding the data for the catch trials, are presented in Table 1 . The reaction time results were consistent with the general alphanumeric category effect. That is, the effect of display size on reaction time was less for between-category than for within-category search. Analyses of variance on mean "yes" and "no" reaction times indicated that the interaction between display size $(1,2$, 4 , and 6 ) and search condition (between vs. within) significantly affected performance for Groups 96 and 192 $[\mathrm{F}(3,66)=9.23, \mathrm{p}<.001, \mathrm{MSe}=2,794.0$, and $\mathrm{F}(3,66)$ $=18.71, \mathrm{p}<.001, \mathrm{MSe}=2,053.7$, respectively]. Also significant was the interaction between display size and response (yes vs. no) $[\mathrm{F}(3,66)=4.90, \mathrm{p}<.005, \mathrm{MSe}$ $=1,861.2$, and $\mathrm{F}(3,66)=9.62, \mathrm{p}<.001$, MSe $=$ $2,375.7$, respectively]. The latter reflected the typical finding that the effect of display size is smaller when the target is present than when the target is absent. The analysis of variance for Group 192 also included practice as a factor; we contrasted performance for the first and second block of 96 trials. Practice did not moderate the category effect; the three-way interaction between practice, search condition, and display size was not significant $[F(3,66)=1.21, p>05, \mathrm{MSe}=1,562.1]$. Practice, however, did improve search rates; the interaction between practice and display size was significant $[F(3,66)$ $=4.01, \mathrm{p}<.05, \mathrm{MSe}=1,562.1]$. Also, practice tended to reduce the difference in reaction time between "yes" and "no" responses; the interaction between practice and response was significant $[\mathrm{F}(1,22)=5.43, \mathrm{p}<.05$, MSe $=2,392.3]$. An examination of the error data provided no evidence that the above results were due to subjects' adopting differential speed-accuracy criteria in the various experimental conditions.

Having obtained evidence for the typical alphanumeric category effect, the main purpose of the experiment was to assess performance on the catch trial. None of the Group 96 or Group 192 subjects in the within-category condition made errors on the catch trial. For the betweencategory condition, however, 5 of 12 subjects in Group 96, as compared with 0 of 12 subjects in Group 192, made errors on the catch trial. (In this and other attempts, we were never able to approach Gleitman and Jonides's, 1976, rate of false alarms, which was $87.5 \%$.) The difference in catch-trial false-alarm rates for the between-category conditions of Groups 96 and 192 
Table 1

Experiment 1: Mean Reaction Times (Milliseconds), Slope of the Mean Reaction Time Function (Miliseconds per Item), and Percentage Errors for the Between-Category and Within-Category Search Conditions for Subjects Receiving 96 Trials (Group 96) and Subjects Receiving 192 Trials (Group 192)

\begin{tabular}{|c|c|c|c|c|c|c|c|c|c|c|c|}
\hline \multirow{3}{*}{$\begin{array}{l}\text { Type of } \\
\text { Search }\end{array}$} & \multirow{3}{*}{$\begin{array}{l}\text { Match With } \\
\text { Target }\end{array}$} & \multicolumn{6}{|c|}{ Reaction Time } & \multicolumn{4}{|c|}{ Errors } \\
\hline & & \multicolumn{4}{|c|}{ Display Size } & \multirow[b]{2}{*}{ Mean } & \multirow[b]{2}{*}{ Slope } & \multicolumn{4}{|c|}{ Display Size } \\
\hline & & 1 & 2 & 4 & 6 & & & 1 & 2 & 4 & 6 \\
\hline \multicolumn{12}{|c|}{ Group 96} \\
\hline Between & Yes & 591 & 593 & 603 & 624 & 603 & 6.6 & 3.5 & 3.5 & 0.7 & 0.7 \\
\hline Category & No & 623 & 607 & 667 & 706 & 651 & 19.1 & 0.7 & 0.7 & 0.7 & 0.7 \\
\hline Within & Yes & 596 & 571 & 653 & 715 & 634 & 27.2 & 1.4 & 3.5 & 1.4 & 2.1 \\
\hline Category & No & 646 & 655 & 712 & 839 & 713 & 38.6 & 7.6 & 2.8 & 0.7 & 2.1 \\
\hline \multicolumn{12}{|c|}{ Group 192: First 96 Trials } \\
\hline Between & Yes & 590 & 577 & 590 & 621 & 595 & 6.9 & 1.4 & 2.1 & 2.4 & 0.7 \\
\hline Category & No & 651 & 648 & 675 & 772 & 687 & 24.0 & 1.0 & 1.0 & 1.0 & 0.3 \\
\hline Within & Yes & 607 & 618 & 683 & 771 & 670 & 33.5 & 0 & 0.3 & 1.4 & 1.4 \\
\hline Category & No & 691 & 697 & 766 & 888 & 761 & 40.0 & 1.7 & 1.4 & 0.3 & 0.7 \\
\hline \multicolumn{12}{|c|}{ Group 192: Second 96 Trials } \\
\hline Between & Yes & 578 & 565 & 599 & 611 & 588 & 8.3 & 2.4 & 3.5 & 4.2 & 1.4 \\
\hline Category & No & 635 & 625 & 651 & 710 & 655 & 15.6 & 2.1 & 1.0 & 1.0 & 0.3 \\
\hline Within & Yes & 577 & 598 & 656 & 679 & 628 & 21.3 & 0 & 2.4 & 3.5 & 3.8 \\
\hline Category & No & 650 & 651 & 672 & 815 & 697 & 31.8 & 2.1 & 1.4 & 0.7 & 1.0 \\
\hline
\end{tabular}

was significant by a Fisher-Yates test of exact probability $(\mathrm{p}<.02)$.

Performance on the catch trial was then contrasted with performance on the immediately preceding, six-item, target-absent trial (see Table 2). In the within-category conditions, subjects in Groups 96 and 192 were slightly more likely to make errors and were slightly faster on the immediately preceding standard trial than on the catch trial. These differences were probably due to small shifts in speed-accuracy criteria. Subjects in the betweencategory conditions did not make any errors on the standard trial preceding the catch trial. Of primary interest were their reaction times for correct "no" responses on the catch trial and the immediately preceding standard trial. For Groups 96 and 192, these responses were substantially slower on the catch trial than on the preceding standard trial. The effect of trial type (standard vs. catch trial) was significant $[\mathrm{F}(1,17)=7.92, \mathrm{p}<.02, \mathrm{MSe}=$
$288,720]$, but neither the amount of preceding practice [Group 96 vs. Group 192; $F(1,17)<1.0$, MSe = $283,423]$ nor the interaction between trial type and practice $[\mathrm{F}(1,17)<1.0, \mathrm{MSe}=288,720]$ significantly affected the time required for correct "no" responses.

\section{Discussion}

The results indicated that practice reduced the size of the catch-trial effect, but did not eliminate it. That is, the false alarms obtained when the catch trial was preceded by 96 standard trials were eliminated when the catch trial was preceded by 192 standard trials, but reaction times for correct "no" responses remained quite slow. It will be recalled from the introduction that the physicalresemblance explanation of the category effect would associate the reduction in the catch-trial effect with slower search rates (as indicated by a steeper slope of the function relating response time to display size). Both would

Table 2

Summary of Performance on Catch Trial and Immediately Preceding Standard Trial for Experiments 1 and 2, Including the Proportions of Subjects Correctly Responding "No" and the Mean Reaction Time (Milliseconds) of their Correct "No" Responses

\begin{tabular}{|c|c|c|c|c|}
\hline & \multicolumn{2}{|c|}{$\begin{array}{c}\text { Proportion of Subjects } \\
\text { Correctly Responding "No" }\end{array}$} & \multicolumn{2}{|c|}{$\begin{array}{c}\text { Reaction Time for } \\
\text { Correct "No" Responses }\end{array}$} \\
\hline & Catch Trial & $\begin{array}{c}\text { Preceding } \\
\text { Standard Trial } \\
\end{array}$ & Catch Trial & $\begin{array}{c}\text { Preceding } \\
\text { Standard Trial }\end{array}$ \\
\hline \multicolumn{5}{|c|}{ Between-Category } \\
\hline Experiment 1: after 96 trials & 0.58 & 1.00 & 1068 & 769 \\
\hline Experiment 1: after 192 trials & 1.00 & 1.00 & 1245 & 643 \\
\hline Experiment 2: after 384 trials & 0.92 & 0.92 & 628 & 627 \\
\hline \multicolumn{5}{|c|}{ Within-Category } \\
\hline Experiment 1: after 96 trials & 1.00 & 0.75 & 805 & 725 \\
\hline Experiment 1 : after 192 trials & 1.00 & 0.83 & 725 & 683 \\
\hline
\end{tabular}


result from an increasingly stringent criterion for determining whether a display item matched the target. A comparison of the two blocks of 96 trials for Group 192 (Table 1) indicated that the search rate for the between-category condition increased only slightly with practice for target-present responses and decreased substantially for target-absent responses.

The results to this point therefore indicated that practice eliminated false alarms on the catch trial, but there was no support for the hypothesis that the practice effect was the result of a shifting decision criterion (as predicted from the physical-resemblance explanation of the category effect). In the experiment that follows, the amount of practice preceding the catch trial was increased to 384 trials. Our purpose was to determine whether this level of practice would eliminate the slow target-absent responses obtained when subjects responded correctly on the catch trial.

\section{EXPERIMENT 2}

The first experiment did not challenge the level-ofidentification explanation of the catch-trial effect. False alarms on the catch trial could have been the result of subjects' initiating target-present responses when they identified the target at the category level. Slow target-absent responses on the catch trial could have resulted from the initiation of target-present responses prior to the specificlevel identification of the target. The slow target-absent responses would reflect the need to inhibit the previously initiated target-present response.

The level-of-identification explanation of the catch-trial data would require that responses on the standard trials preceding the catch trial be initiated on the basis of the category-level identification of the target. In order to test this hypothesis, we compared between-category search under two conditions: (1) when subjects searched for the presence of a particular digit (this is the standard betweencategory condition), and (2) when subjects searched for the presence of any digit. Taylor (1978) has reported the results of an experiment contrasting these conditions. $\mathrm{He}$ found, for both target-present ("yes") and target-absent ("no") responses, that search rates were the same in the particular-digit and any-digit conditions. However, in both cases, he also found that subjects' overall reaction times were faster in the particular-digit condition than the anydigit condition. If subjects' responses in the particulardigit condition were based on the category-level identification of the target, they would not have been faster than their responses in the any-digit condition. Although Taylor's (1978) results are inconsistent with the level-ofidentification interpretation of the catch-trial effect, they were based on experimental sessions ( 5 days, 432 trials per day) that were substantially longer than the practice levels we found influenced the catch-trial effect in Experiment 1 . It seemed possible that for the low levels of practice at which the catch-trial effect was obtained, there would be relatively little difference in reaction time be- tween the particular-digit and any-digit conditions. With additional practice, the level-of-identification explanation would predict that the reduction in the catch-trial effect would be accompanied by an increase in the difference between the particular-digit and any-digit conditions. Both would be due to the greater likelihood of specific-level target identification with increased practice levels.

As indicated earlier, the second purpose of this experiment was to determine whether increasing the number of practice trials preceding the catch trial from 192 to 384 would eliminate slow target-absent responses on the catch trial (192 trials were sufficient to eliminate false alarms). If so, we could again evaluate whether this reduction in the catch-trial effect would be accompanied by the slower search rates predicted by the physical-resemblance explanation of the catch-trial effect.

\section{Method}

Subjects. The subjects participating in this experiment were 12 undergraduate students at Florida Atlantic University. Each was paid $\$ 2$ for participating.

Stimuli and Design. The stimuli presented in this experiment were the 192 between-category displays described in Experiment 1. On half the trials, a particular digit was specified prior to the display; on the other half, subjects were told to search for any digit. The particular-digit and any-digit trials were randomly mixed and assigned in a balanced manner to the digit-present and digit-absent displays. Therefore, each block of 48 trials included 24 trials requiring "yes" responses (12 required search for a particular digit and 12 for any digit) and 24 trials requiring "no" responses (again equally divided between the particular-digit and any-digit conditions).

The same four blocks of 48 trials used in the previous experiment were presented to subjects, with each subject again assigned to one of four orders (Latin square) of the four blocks. The sequence of four blocks was presented twice to each subject, resulting in a total of 384 trials (for purposes of comparison, this will be referred to as Group 384). The stimulus displays in the second set of four blocks were identical to the displays in the first set, but the target specification prior to each display was changed. If a display was preceded by the specification of any digit during the first set of 192 trials, it was preceded by the specification of a particular digit when it appeared again during the second set of 192 trials, and vice versa. The 384 experimental trials were preceded by 48 warm-up trials. The 385 th trial was a catch trial identical to the one used in the between-category condition of the preceding experiment.

\section{Results}

Mean reaction times for correct responses and percentage errors, both excluding the data for the catch trials, are presented in Table 3. As can be seen in the table, overall (mean) reaction times were consistently faster in the particular-digit than in the any-digit condition for both "yes" and "no" responses, both early and late in practice (this difference was maintained when the data were decomposed into blocks of 96 trials). The effect of search condition (particular digit vs. any digit) was significant $[\mathrm{F}(1,11)=148.21, \mathrm{p}<.001, \mathrm{MSe}=1,288.7]$, but its interactions with response ("yes" vs. "no") $[\mathrm{F}(1,11)=$ $1.50, \mathrm{p}>.05, \mathrm{MSe}=1,720.0]$ and practice $[\mathrm{F}(1,11)$ $=2.18, \mathrm{p}>.05, \mathrm{MSe}=931.2]$ were not significant. The primary effect of practice was to speed up search rates for target-absent responses in the any-digit condition. The 
Table 3

Mean Reaction Time (Milliseconds), Slope of the Mean Reaction Time Function (Milliseconds per Item), and Percentage Errors for the Particular-Digit and Any-Digit Versions of Between-Category Search in Experiment 2

\begin{tabular}{|c|c|c|c|c|c|c|c|c|c|c|c|}
\hline \multirow{3}{*}{$\begin{array}{l}\text { Match With } \\
\text { Target }\end{array}$} & \multirow{3}{*}{$\begin{array}{c}\text { Target } \\
\text { Specification }\end{array}$} & \multicolumn{6}{|c|}{ Reaction Time } & \multicolumn{4}{|c|}{ Errors } \\
\hline & & \multicolumn{4}{|c|}{ Display Size } & \multirow[b]{2}{*}{ Mean } & \multirow[b]{2}{*}{ Slope } & \multicolumn{4}{|c|}{ Display Size } \\
\hline & & 1 & 2 & 4 & 6 & & & 1 & 2 & 4 & 6 \\
\hline \multicolumn{12}{|c|}{ First 192 Trials } \\
\hline $\begin{array}{l}\text { Yes } \\
\text { Yes }\end{array}$ & $\begin{array}{l}\text { Particular Digit } \\
\text { Any Digit }\end{array}$ & $\begin{array}{l}482 \\
511\end{array}$ & $\begin{array}{l}466 \\
525\end{array}$ & $\begin{array}{l}481 \\
535\end{array}$ & $\begin{array}{l}523 \\
576\end{array}$ & $\begin{array}{l}488 \\
537\end{array}$ & $\begin{array}{r}8.9 \\
12.2\end{array}$ & $\begin{array}{l}4.9 \\
3.5\end{array}$ & $\begin{array}{l}4.9 \\
6.3\end{array}$ & $\begin{array}{l}8.3 \\
7.6\end{array}$ & $\begin{array}{l}4.2 \\
2.8\end{array}$ \\
\hline $\begin{array}{l}\text { No } \\
\text { No }\end{array}$ & $\begin{array}{l}\text { Particular Digit } \\
\text { Any Digit }\end{array}$ & $\begin{array}{l}527 \\
539\end{array}$ & $\begin{array}{l}552 \\
559\end{array}$ & $\begin{array}{l}586 \\
629\end{array}$ & $\begin{array}{l}605 \\
742\end{array}$ & $\begin{array}{l}568 \\
617\end{array}$ & $\begin{array}{l}15.4 \\
40.7\end{array}$ & $\begin{array}{l}3.5 \\
5.6\end{array}$ & $\begin{array}{l}6.9 \\
2.1\end{array}$ & $\begin{array}{l}3.5 \\
2.8\end{array}$ & $\begin{array}{l}4.2 \\
4.9\end{array}$ \\
\hline \multicolumn{12}{|c|}{ Second 192 Trials } \\
\hline $\begin{array}{l}\text { Yes } \\
\text { Yes }\end{array}$ & $\begin{array}{l}\text { Particular Digit } \\
\text { Any Digit }\end{array}$ & $\begin{array}{l}443 \\
505\end{array}$ & $\begin{array}{l}470 \\
494\end{array}$ & $\begin{array}{l}453 \\
519\end{array}$ & $\begin{array}{l}477 \\
529\end{array}$ & $\begin{array}{l}461 \\
512\end{array}$ & $\begin{array}{l}4.6 \\
6.1\end{array}$ & $\begin{array}{l}3.5 \\
5.6\end{array}$ & $\begin{array}{l}1.4 \\
3.5\end{array}$ & $\begin{array}{l}6.3 \\
2.8\end{array}$ & $\begin{array}{l}3.5 \\
6.3\end{array}$ \\
\hline $\begin{array}{l}\text { No } \\
\text { No }\end{array}$ & $\begin{array}{l}\text { Particular Digit } \\
\text { Any Digit }\end{array}$ & $\begin{array}{l}509 \\
545\end{array}$ & $\begin{array}{l}509 \\
543\end{array}$ & $\begin{array}{l}540 \\
576\end{array}$ & $\begin{array}{l}604 \\
614\end{array}$ & $\begin{array}{l}541 \\
570\end{array}$ & $\begin{array}{l}19.3 \\
14.6\end{array}$ & $\begin{array}{l}4.2 \\
3.5\end{array}$ & $\begin{array}{l}6.9 \\
4.2\end{array}$ & $\begin{array}{l}3.5 \\
2.1\end{array}$ & $\begin{array}{l}4.2 \\
6.9\end{array}$ \\
\hline
\end{tabular}

Note-Subjects received 384 trials (Group 384).

latter was responsible for the significant four-way interaction between search condition, display size, response condition, and practice $[\mathrm{F}(3,33)=8.28, \mathrm{p}<.001$, MSe $=1,082.6]$. An examination of errors provided no indication that the results described above were due to subjects' adopting differential speed-accuracy criteria in the various experimental conditions.

Only 1 of the 12 subjects made a false-alarm error on the catch trial presented at the end of the experimental sequence, a rate of false alarms that matched the rate obtained for the most immediately preceding six-item, targetabsent display (with the target specified as a particular digit). As can also be seen in Table 2 , the mean reaction times for correct "no" responses were virtually identical for the catch trial and the immediately preceding standard trial $[\mathrm{t}(9)<1.0] .^{3}$ Extending the amount of practice preceding the catch trial from 192 trials to 384 trials therefore eliminated the reaction time aspect of the catchtrial effect. An examination of subjects' search rates in the particular-digit condition of Experiment 2 provided no evidence that practice also resulted in slower search. Search rates slowed with practice for target-absent responses, but speeded up by a like amount for targetpresent responses.

\section{Discussion}

The reaction time data meshed well with the results of previous studies. As in Taylor (1978), "yes"' responses were slower in the any-digit condition than in the particular-digit condition, but search rates were the same in both conditions. Also as in Taylor (1978), this result was obtained at all levels of practice. The primary change produced by practice was the sharp reduction in search rates for "no" responses in the any-digit condition. This practice effect was in accord with the results of an experiment by Egeth, Jonides, and Wall (1972), which used practice blocks that were comparable in size to those used in this experiment (although they were presented on successive days rather than the same experimental session).
The results obtained on the catch trial continued the trend of Experiment 1. With sufficient preceding practice (384 trials), the catch-trial effect was completely eliminated. This change in the catch-trial effect with practice was not accompanied by the slower search rates that were predicted from the physical-resemblance explanation of the category effect. It was also not accompanied by the increased difference in reaction time between the particular-digit and any-digit conditions that was predicted from the level-of-identification explanation.

The additional 192 practice trials introduced in this experiment were all any-digit trials. If anything, such trials would be expected to encourage the maintenance of a strategy involving the category-level identification of display items and, thereby, the continuation of the catch-trial effect. The elimination of the catch-trial effect therefore suggested that general experience with the particular style of characters presented in the display was at least as important in eliminating the catch-trial effect as the processing demands of the search task.

\section{GENERAL DISCUSSION}

The primary experimental finding in this study was that practice reduced, and ultimately eliminated, the catch-trial effect. When the catch trial occurred after 96 standard between-category trials, subjects made either incorrect target-present responses or very slow, correct targetabsent responses. When 192 trials preceded the catch trial, false alarms were eliminated, but subjects continued producing slow target-absent responses. Only when 384 practice trials preceded the catch trial were slow targetabsent responses eliminated.

The results were inconsistent with Schneider and Shiffrin's (1977) claim that the category effect in visual search is the result of an automatic attention response to category-level information. Since practice tends to foster automaticity, it should have increased rather than decreased the catch-trial effect. The results were also in- 
consistent with the level-of-identification explanation of the catch-trial effect. The latter would attribute the catchtrial effect to the initiation of responses on the basis of category-level identification. The reduction of the catchtrial effect with practice would be attributed to specificlevel identification preceding response initiation. However, the results of Experiment 2 were inconsistent with this explanation. Reaction times in this experiment were faster for the particular-digit than for the any-digit condition at all levels of practice.

The physical-resemblance explanation of the catch-trial effect would attribute its decrease with practice to the development of more stringent criteria for determining whether a display item matched the target. There was, however, no evidence for the slowing of search rates with practice that would support the hypothesized criterion change with practice. Given that practice customarily results in faster search rates (Schneider \& Schiffrin, 1977), failure to find evidence in support of the physicalresemblance explanation was not surprising. Although it is possible to speculate about additional effects of practice that might have masked the hypothesized change in criterion, it remains the case that an increase rather than a decrease in the catch-trial effect with practice would have been more amenable with Duncan's (1983) physicalresemblance explanation.

As indicated earlier, Duncan (1983) argued that withincategory search is faster than between-category search because items in the display are more difficult to reject as nontargets when they resemble the target (as in withincategory search) than when they do not resemble the target (as in between-category search). The results reported in this study can be accounted for by a modification of this explanation. The modification distinguishes between attributes of the target that are shared with other members of the target's category (resemblance information) and attributes that are specific to the target and therefore distinguish it from other members of its category. Accordingly, visual search would require testing each display item for the presence of attributes shared with other members of the target's category and/or attributes specific to the particular target.

Our data indicate that early in practice attention to resemblance information took precedence over attention to item-specific attributes. ${ }^{4}$ The cost of testing each display item only for the presence of category-level resemblances was the relatively strong catch-trial effect obtained early in practice. The elimination of the catch-trial effect with further practice could then be explained by increased attention to item-specific attributes.

Why were relatively low levels of practice sufficient to reduce and eventually eliminate the catch-trial effect? Certainly 192-384 practice trials (plus 48 warm-up trials) were not enough to alter long-established differences in perceptual disciminability for alphanumeric characters. A more likely possibility is that practice provided subjects with the opportunity to "adjust" to the particular type font they were seeing. Although there was nothing peculiar about the type font, some period of adjustment may have nonetheless been required. It might allow subjects to determine how the resemblance and item-specific attributes abstracted from previous experiences with alphanumeric characters were embodied in the particualr characters used in these experiments. Subjectively, this may have resulted in the integration of these attributes, resulting in the experience of a template-like search. Covertly, it may have resulted in the formation of decision pools that combined simultaneously available resemblance and item-specific information (Miller, 1981, 1982). The formation of such decision pools would allow for a less stringent decision criterion than would be necessary for each of the informational components working independently. On this basis, increased attention to itemspecific information with extended practice would eliminate false alarms and slow responses on catch trials, and would also lead to faster search rates on noncatch trials.

The crucial evidence for the physical-resemblance explanation of the category effect was its elimination when both between-category and within-category search involved targets that resembled nontarget items in the display (Corcoran \& Jackson, 1977; Krueger, 1984). However, an important factor that must be taken into consideration is that the members of most categories differ in the extent to which they are typical of their category. Rosch and Mervis (1975) have shown that the more typical a stimulus is of its category, the more it tends to resemble members of its own category and the less it tends to resemble members of contrasting categories. Stimuli that resemble members of contrasting categories as strongly as members of their own category are generally considered atypical of their category. From this point of view, the alphanumeric characters selected by Corcoran and Jackson (1977) and Krueger (1984) to match betweencategory and within-category resemblance were not typical members of the alphanumeric categories. When such atypical members serve as targets, attention to resemblance information is ineffective, since these targets are selected to resemble the nontarget items in the display. Target detection would then depend on attention to itemspecific information, eliminating the advantage of between-category over within-category search. However, when the specified target is typical of its category, it resembles members of its own category more than members of contrasting categories. Only then would attention to resemblance information be effective in detecting the target, and an advantage be obtained for between-category search.

Our modification of Duncan's (1983) physicalresemblance explanation to account for the effects or practice on catch trials does not impair its ability to explain the various phenomena associated with the category effect. It does, however, provide a significant conceptual change. Duncan (1983) has asserted that the category effect is the result of uncontrolled differences in physical resemblance. Our modification reintroduces the idea, in- 
herent in Gleitman and Jonides' (1976) early work, that subjects' knowledge of the attribute structures for alphanumeric categories can influence visual search.

\section{REFERENCES}

Brand, J. (1971). Classification without identification in visual search. Quarterly Journal of Experimental Psychology, 23, 178-186.

CORCORAN, D. W. J., \& JACKSON, A. (1977). Basic processes and strategies in visual search. In S. Dornic (Ed.), Attention and performance VI. Hillsdale, NJ: Erlbaum.

DICK, A. O. (1971). Processing time for naming and categorization of letters and numbers. Perception \& Psychophysics, 9(3B), 350-352.

Duncan J. (1983). Category effects in visual search: A failure to replicate the "oh-zero" phenomenon. Perception \& Psychophysics, 34, 221-232.

EgETh, H., Jonides, J., \& WALL, S. (1972). Parallel processing of multielement displays. Cognitive Psychology, 3, 674-698.

Francolini, C. M., \& EgeTh, H. E. (1979). Perceptual selectivity is task dependent: The pop-out effect poops out. Perception \& Psychophysics, 25, 99-110.

Gleitman, H., \& JonidEs, J. (1976). The cost of categorization in visual search: Incomplete processing of target and field items. Perception \& Psychophysics, 20, 281-288.

Gleitman, H., \& Jonides, J. (1978). The effect of set on categorization in visual search. Perception \& Psychophysics, 24, 361-368.

INGLING, N. (1972). Categorization: A mechanism for rapid information processing. Journal of Experimental Psychology, 94, 239-243.

Jonides, J., \& Gleitman, H. (1972). A conceptual category effect in visual search: $\mathrm{O}$ as letter or as digit. Perception \& Psychophysics, $12,457-460$.

JoniDEs, J., \& GleitMan, H. (1976). The benefit of categorization in visual search: Target location without identification. Perception \& Psychophysics, 20, 289-298.

KRUEGER, L. E. (1984). The category effect in visual search depends on physical rather than conceptual differences. Perception \& Psychophysics, 35, 536-542.

MiLLER, J. (1981). Global precedence in attention and decision. Journal of Experimental Psychology: Human Perception and Performance, 7, 1161-1174.

MilleR, J. (1982). Divided attention: Evidence for coactivation with redundant signals. Cognitive Psychology, 14, 247-279.

NiCKERSON, R. S. (1973). Can characters be classified directly as digits vs letters or must they be identified first? Memory \& Cognition, 1 , 477-484.

Rosch, E., \& Mervis, C. (1975). Family resemblances: Studies in the internal structure of categories. Cognitive Psychology, 7, 573-605.

SCHNEIDER, W., \& SHIFFrin, R. M. (1977). Controlled and automatic human information processing: I. Detection, search, and attention. Psychological Review, 84, 1-66.

TAYLOR, D. A. (1978). Identification and categorization of letters and digits. Journal of Experimental Psychology: Human Perception and Performance, 4, 423-439.

\section{NOTES}

1. Between-category search in this experiment, as well as in the experiment that follows, always involved searching for digits in a display of letters. The omission of the inverse conditions was based on the results of numerous experiments which had indicated that the typical category effect is obtained when subjects search for letters among digits or digits among letters (Duncan, 1983; Gleitman \& Jonides, 1976, 1978; Jonides \& Gleitman, 1972, 1976; Taylor, 1978).

2. The reaction time data reported in Table 2 included only those subjects with correct "no" responses on both the catch trial and the preceding standard trial. The analysis of variance was performed only for these subjects (7 subjects in Group 96, 12 in Group 192). The unequal numbers of subjects required the use of a least squares procedure. The inclusion of reaction times for all correct "no" responses would have only slightly altered the means reported in Table 2.

3. As in Experiment 1, the reaction time data reported in Table 2 included only those subjects with correct "no" responses on both the catch trial and the preceding standard trial (10 of the 12 subjects in Group 384). The inclusion of reaction times for all correct "no" responses would have only slightly altered the means reported in Table 2 .

4. In specifying that attention to resemblance information precedes attention to item-specific information, our reasoning followed Miller's (1981) analysis of the processing of global and local pattern information. He argued that global and local information become available to a central processor over a similar time course, but attentional priority is given to global information. In a similar vein, we allow that resemblance and item-specific information also become available to a central processor over a similar time course, but attentional priority is given to resemblance information (early in practice).

(Manuscript received September 17, 1984; revision accepted for publication January 2, 1985.) 